\title{
Probiotics for Preterm Neonates: What Will It Take to Change Clinical Practice?
}

\author{
N. Ofek Shlomai ${ }^{a, f}$ G. Deshpande ${ }^{\text {d, e }}$ S. Rao ${ }^{b, c}$ S. Patole ${ }^{a, c}$ \\ a Department of Neonatal Paediatrics, KEM Hospital for Women, ${ }^{b}$ Department of Neonatal Paediatrics, Princess \\ Margaret Hospital for Children, and ${ }^{\mathrm{C} C e n t r e}$ for Neonatal Research and Education, School of Paediatrics and Child \\ Health, University of Western Australia, Perth, W.A., and d Department of Neonatology, Nepean Hospital Sydney,

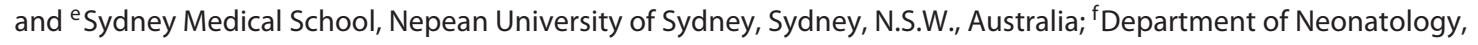 \\ Hadassah Medical Centre and Hebrew University, Jerusalem, Israel
}

\section{Key Words}

Neonates · Practice $\cdot$ Probiotics $\cdot$ Routine

\begin{abstract}
Necrotizing enterocolitis (NEC) is a major cause of mortality (25\%) and morbidity including recurrent sepsis, dependence on parenteral nutrition, need for surgery, and survival with short bowel syndrome in preterm very low birth weight infants. Mortality (45-100\%) and morbidity including the risk of long-term neurodevelopmental impairment are higher in extremely preterm infants needing surgery for NEC. Systematic reviews of randomized controlled trials (RCT) indicate that probiotics significantly reduce the risk of NEC (RR 0.39; $95 \% \mathrm{Cl} 0.29-0.52 ; \mathrm{p}<0.00001)$ and all-cause mortality (RR $0.52 ; 95 \% \mathrm{Cl} 0.40-0.69 ; \mathrm{p}<0.00001$ ) while facilitating enteral feeds in preterm infants. At present, data from $25 \mathrm{RCT}(\sim 5,000$ neonates) and reports on routine use ( 3,000 neonates) indicates that significant adverse effects of probiotics are rare. Despite the robust evidence, there is still reluctance in incorporating routine probiotic prophylaxis in clinical practice. If the goal is to have zero tolerance for NEC, then probiotic prophylaxis must be adopted as soon as possible. Current gaps in knowledge can be addressed by continued research while providing routine probiotic supplementation. We believe that the concept of evidence-based practice of medi-
\end{abstract}

cine has been stretched too far in this case. Trial sequential analysis has already shown that the evidence for probiotic supplementation was conclusive after 10 trials. Results of the ongoing trials are unlikely to change the conclusions of the systematic reviews significantly. Currently we are at trial number 25; how many more trials do we need? What will it take to change clinical practice?

(c) 2013 S. Karger AG, Basel

Necrotizing enterocolitis (NEC; $\geq$ stage II) is one of the major causes of mortality and morbidity in preterm infants. NEC affects about $6-7 \%$ of very low birth weight (VLBW; $<1,500 \mathrm{~g}$ ) infants, with mortality $\sim 25 \%$ and morbidity that includes recurrent sepsis, complications of prolonged parenteral nutrition, the need for surgery, and survival with short bowel syndrome [1]. Mortality (45-100\%), and importantly the risk of long-term neurodevelopmental impairment (NDI), is higher in extremely low birth weight (ELBW) infants needing surgery for the illness [1]. The economic burden of NEC is significant considering the prolonged hospital stay due to multiple complications. The USA alone is estimated to spend $\sim 1$ billion dollars per year for NEC, not accounting for the cost of caring for its survivors with NDI [1].

\section{KARGER}

E-Mail karger@karger.com

www.karger.com/neo
(C) 2013 S. Karger AG, Basel

$1661-7800 / 14 / 1051-0064 \$ 39.50 / 0$
Prof. Sanjay Patole, MD, DCH, FRACP, MSc, DrPH

Department of Neonatal Paediatrics, KEM Hospital for Women 374 Bagot Road

Subiaco, City of Perth, WA 6008 (Australia)

E-Mail sanjay.patole@ health.wa.gov.au 
Table 1. Prophylactic interventions reducing the risk of NEC and death in preterm neonates

\begin{tabular}{|c|c|c|c|c|}
\hline Intervention & First author (year) & $\begin{array}{l}\text { Sample } \\
\text { size, } \mathrm{n}\end{array}$ & Study type & Effect size and significance \\
\hline \multicolumn{5}{|l|}{$N E C$} \\
\hline Antenatal glucocorticoids & Roberts [28] (2010) & 4,269 & Systematic review of RCT & RR 0.46; 95\% CI 0.29-0.74; $\mathrm{p}=0.0012$ \\
\hline Breast milk & McGuire [29] (2003) & 343 & Systematic review of RCT & RR $0.25 ; 95 \%$ CI $0.06-0.98 ; \mathrm{p}=0.015$ \\
\hline $\begin{array}{l}\text { Standardized feeding } \\
\text { protocols }\end{array}$ & Patole [30] (2005) & 453 & $\begin{array}{l}\text { Systematic review of } \\
\text { observational studies }\end{array}$ & RR $0.13 ; 95 \%$ CI $0.03-0.5 ; \mathrm{p}=0.03$ \\
\hline $\begin{array}{l}\text { Bovine lactoferrin }+ \text { LGG } \\
\text { (neonates }<1 \mathrm{~kg} \text { ) }\end{array}$ & Pammi [32] (2011) & 472 & Systematic review of RCT & RR $0.34 ; 95 \%$ CI $0.17-0.70 ; p=0.002$ \\
\hline \multicolumn{5}{|l|}{ All-cause mortality } \\
\hline Probiotics & Wang [2] (2012) & 3,816 & Systematic review of RCT & RR 0.56; 95\% CI 0.43-0.73; $p<0.0001$ \\
\hline Antenatal glucocorticoids & Roberts [28] (2010) & 4,269 & Systematic review of RCT & RR $0.69 ; 95 \%$ CI $0.58-0.81 ; \mathrm{p}<0.00001$ \\
\hline
\end{tabular}

Probiotics are live microbial supplements that colonize the gut while providing benefits to the host. Their benefits include an improved gut barrier, enhanced mucosal IgA responses, and increased production of antiinflammatory cytokines. The rationale for probiotic prophylaxis for NEC relates to the role of bacterial colonization of the gut in the pathogenesis of the illness. Similar to earlier reviews, results of a recent systematic review and meta-analysis of 20 randomized controlled trials (RCT; total sample size $=3,816$ ) confirm that probiotic supplementation significantly reduces the risk of NEC (RR 0.33; 95\% CI 0.24-0.46; $\mathrm{p}<0.00001$ ) and all-cause mortality (RR 0.56 ; 95\% CI 0.43-0.73; p < 0.0001) without any significant adverse effects, including probiotic sepsis, in preterm VLBW infants [2]. Experts agree that probiotics reduce the risk of NEC and death, and the evidence for mortality reduction is as conclusive as that for other wellestablished interventions such as antenatal corticosteroids, surfactant, and cooling [3-5]. Others passionately remind us that 'we will never conquer NEC until we strive to significantly reduce its incidence; otherwise we will not be able to look parents in the eyes and say that their preterm infant has avoided all the major risks of NDI' [6]. Despite the seriousness of the underlying issue, there is still a lot of reluctance in adopting probiotic prophylaxis for reducing the risk of NEC and death in preterm infants [7].

Probiotics have the best effect size (RR 0.33; 95\% CI $0.24-0.46 ; \mathrm{p}<0.00001)$ compared with other strategies for preventing NEC (table 1) [2]. We reviewed the Cochrane systematic reviews database for primary prophylactic strategies $(n=49)$ for preterm infants and selected those that have been incorporated in clinical practice. Sixteen of these 25 strategies have been reported as beneficial in improving the primary outcome, with only 4 reducing mortality. Compared with other strategies that reduce mortality, probiotics have the largest effect size (RR 0.56; 95\% CI 0.43-0.73; p < 0.0001) (table 1) [2].

Primary prophylaxis involves exposing a large population of healthy subjects to an intervention for preventing disease in only a few. It is therefore crucial to prove that the intervention is very safe. Demonstrating the safety of probiotics in preterm infants is more critical considering their immunologic immaturity and decreased intestinal barrier integrity. The potential adverse effects of probiotics include probiotic sepsis, antibiotic resistance, and altered long-term immune responses. A review [8] of the level of evidence for probiotics in preterm infants concluded that so far no side effects have been reported and long-term outcomes are reassuring. Probiotic sepsis, even if it occurs, is easy to treat. Experts argue that infection with lactobacilli is preferable over potential pathogens like Klebsiella, Enterobacter, or yeast [9]. The availability of effective killed/inactivated probiotic strains or probiotic components may overcome the issue of probiotic sepsis [10].

Data from routine use rather than RCT is important for optimal assessment of the adverse effects of any interven- 


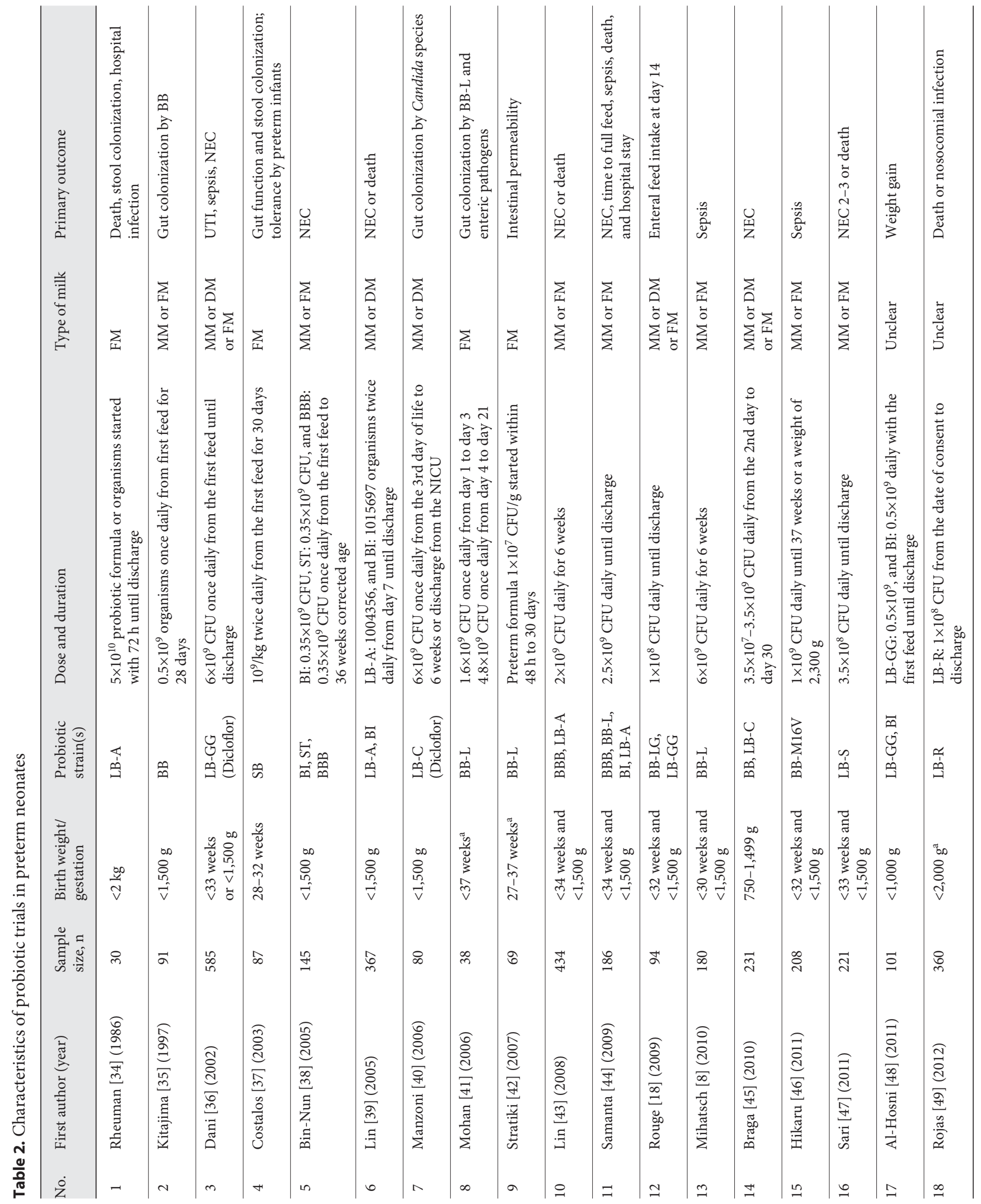




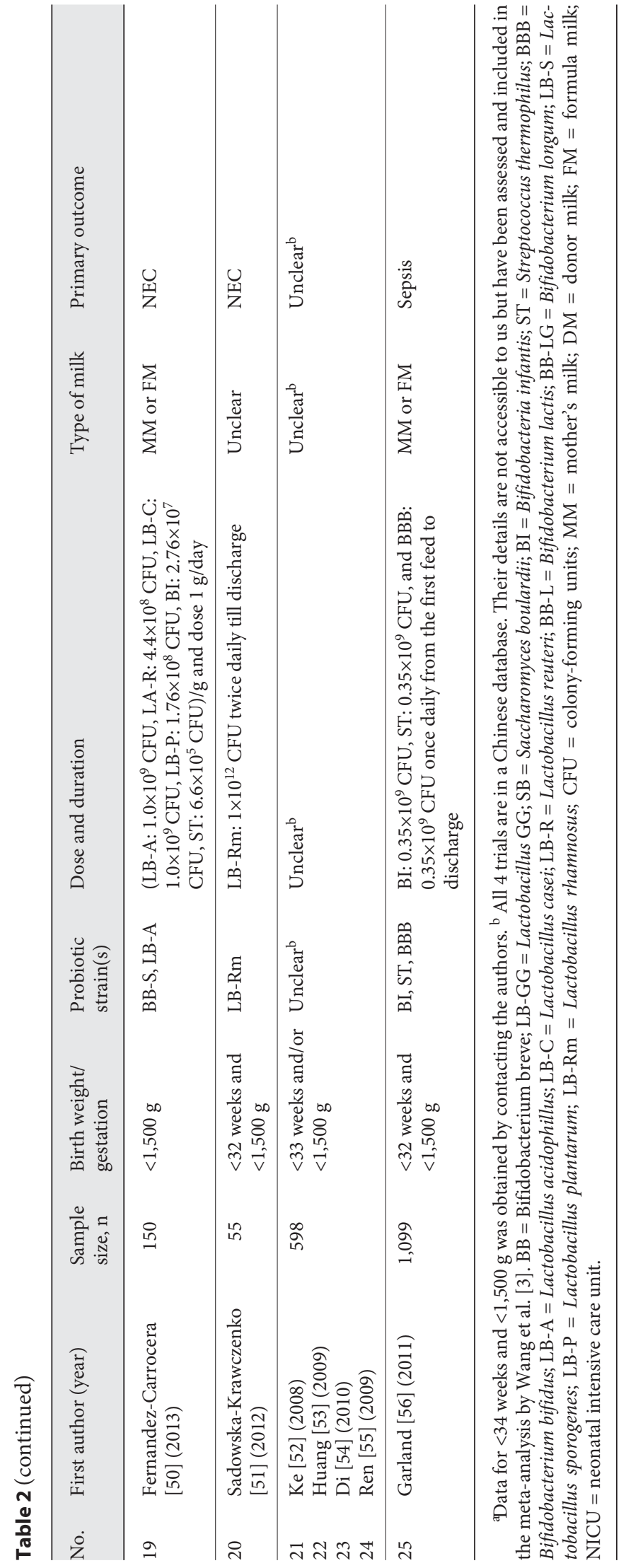

tion. Bonsante et al. [11] reported on 1,130 preterm infants (gestation: 24-31 weeks) given routine probiotic prophylaxis. The risk of NEC, death, late-onset sepsis, and rectal bleeding was reduced and full feeds were reached earlier without any adverse effects. Hunter et al. [12] assessed the impact of routine Lactobacillus reuteri supplementation on NEC in ELBW infants $(\leq 1,000 \mathrm{~g})$. The incidence of NEC was significantly lower in probiotic-treated [2/79 (2.5\%)] versus untreated infants from a historical cohort [35/232 (15.1\%)]. Probiotic supplementation prevented 1 NEC case for every 8 infants given the prophylaxis [12]. No probiotic-related adverse events occurred. The reports by Luoto et al. [13] $(n=644)$ and Manzoni et al. [14] $(n=811)$ also indicate the safety of routine probiotic supplementation in preterm VLBW infants practiced for 6-12 years $[13,14]$. Probiotic prophylaxis has not been associated with long-term NDI in preterm infants $[15,16]$. Romeo et al. [17] reported that probiotic-treated infants had a significantly lower incidence of NDI at 12 months. There is little evidence that antibiotic resistance is a significant problem with lactobacilli and bifidobacteria [18]. These strains have a high degree of genetic stability, but the risk justifies continual assessment [19]. The previously reported risk of sensitization in infants exposed to probiotics has not been apparent in the long term [20].

Adopting an effective prophylaxis in a low-incidence setting may be difficult if adverse effects are a concern because many who are not at risk would unnecessarily be exposed to the its potential adverse effects, even if they are rare. However, systematic reviews show the safety and efficacy of probiotics even when the incidence of NEC is low $(<6 \%)$ [2].

Considering that severe adverse effects are rare, a reasonably sized clinical study would be insufficient to detect a two-fold rise in the rate of an adverse effect with a $1 \%$ incidence. Current evidence from 25 RCT $(\sim 5,000$ infants) and the reports on routine use $(\sim 3,000)$ indicate that significant adverse effects of probiotics are rare (table 2).

If the goal is to have 'zero tolerance' [6] for NEC, then probiotic prophylaxis must be adopted as the most effective strategy to reduce the risk of this disastrous illness associated with a huge health burden, and immense suffering [1]. This globally available intervention that significantly reduces death and NEC at less than a dollar per day should not be denied to preterm infants if we are to look their parents in the eyes without any hesitation to say that we have done everything for their baby [6].

We have provided evidence-based guidelines for the practical aspects of probiotic supplementation (strain se- 
lection, dose, duration, surveillance, etc.), and for dealing with nonclinical but important issues (regulatory requirements, product format, etc.) [21] and addressed all concerns raised by researchers, including inadequate data on extremely preterm/ELBW infants, reproducibility in different set-ups, and the role of breast milk [22]. Others have pointed out the ethics and politics of probiotics for preterm infants [7]. Our experience in introducing routine probiotic supplementation in Australia confirms that, just as in other nations including the USA [23], access to clinically effective and safe probiotic products is not difficult $[11-14,21]$. Defining probiotics as 'foods for specialized health use' or 'biotherapeutic agents' may overcome the regulatory difficulties while not compromising on quality $[21,24]$. Cooperation between all stakeholders is needed to increase the availability of high-quality probiotics provided there is a will to do so [21].

Assessment of the most effective strains (singularly or in combination), dose, duration, and mechanisms of benefits of probiotics does not need placebo-controlled trials. Current evidence from RCT and observational studies indicates the safety and efficacy of probiotics in extremely preterm neonates who are at the highest risk of NEC, death and feed intolerance. Investigators have voiced a concern that 'the microbiota of a preterm infant without a stable-background gut flora may be significantly skewed by the intentional colonization with billions of organisms in a narrow group of probiotics' [25]. We believe that introducing billions of probiotic microorgan- isms, if at all, will skew the unstable and less diverse flora towards being more stable and diverse and potentially less pathogenic. RCT comparing single versus multistrain/species probiotics can address the concern about introducing a narrow group of probiotics. Adopting the purist's view of waiting until the fine details of the various mechanisms of the benefits of probiotics are understood is unrealistic and perhaps unjustified in view of the available evidence.

We believe that the concept of evidence-based practice of medicine has been stretched too far in the case of probiotics for preterm neonates. Many level III neonatal units in Japan, Italy, Finland, and Colombia have been using probiotics routinely for over a decade and have not reported any significant adverse effects [21]. Trial sequential analysis has already shown that the evidence for probiotic supplementation was conclusive after 10 trials [26]. Experts had commented that the results of the ongoing (PiPS, UK: ISRCTN No. 05511098; ProPrems, Australia: ACTRN012607000144415) trials are unlikely to change the conclusions of the systematic reviews significantly $[3,4]$. The preliminary results of the ProPrems trial support the current evidence that probiotics do not reduce the risk of late onset sepsis (primary outcome) but can reduce the risk of NEC (secondary outcome, not powered for) even in the presence of a low baseline incidence $(4.4 \%)$ of the illness [27]. Currently we are at trial number 25; how many more trials do we need to change clinical practice? At what potential cost?

\section{References}

1 Lemons JA, Bauer CR, Oh W, Korones SB, Papile LA, Stoll BJ, Verter J, Temprosa M, Wright LL, Ehrenkranz RA, Fanaroff AA, Stark A, Carlo W, Tyson JE, Donovan EF, Shankaran S, Stevenson DK: Very low birth weight outcomes of the National Institute of Child health and human development neonatal research network, January 1995 through December 1996. NICHD Neonatal Research Network. Pediatrics 2001;107:E1.

$\checkmark 2$ Wang Q, Dong J, Zhu Y: Probiotic supplement reduces risk of necrotizing enterocolitis and mortality in preterm very low-birthweight infants: an updated meta-analysis of 20 randomized, controlled trials. J Pediatr Surg 2012;47:241-248.

3 Barrington KJ: Review: probiotics prevented necrotising enterocolitis and reduced mortality in preterm neonates. Arch Dis Child Educ Pract Ed 2011;96:199.
4 Tarnow-Mordi WO, Wilkinson D, Trivedi A, Brok J: Probiotics reduce all-cause mortality and necrotizing enterocolitis: it is time to change practice. Pediatrics 2010;125:10681070 .

$\checkmark 5$ Alfaleh K, Anabrees J, Bassler D: Probiotics reduce the risk of necrotizing enterocolitis in preterm infants: a meta-analysis. Neonatology 2010;97:93-99.

-6 Swanson JR: Necrotizing enterocolitis: is it time for zero tolerance? J Perinatol 2013;33: $1-2$.

7 Janvier A, Lantos J, Barrington K: The politics of probiotics: probiotics, necrotizing enterocolitis and the ethics of neonatal research. Acta Paediatr 2013;102:116-118.

8 Mihatsch WA, Vossbeck S, Eikmanns B, Hoegel J, Pohlandt F: Effect of Bifidobacterium lactis on the incidence of nosocomial infections in very-low-birth-weight infants: a randomized controlled trial. Neonatology 2010; 98:156-163.
Kliegman RM: Oral probiotics reduce the incidence and severity of necrotizing enterocolitis in very low birth weight infants. J Pediatr 2005; 146:710.

-10 Awad H, Mokhtar H, Imam SS, Gad GI, Hafez $\mathrm{H}$, Aboushady N: Comparison between killed and living probiotic usage versus placebo for the prevention of necrotizing enterocolitis and sepsis in neonates. Pak J Biol Sci 2010;13: 253-262.

11 Bonsante F, Iacobelli S, Gouyon JB: Routine probiotic use in very preterm infants: retrospective comparison of two cohorts. Am J Perinatol 2013;30:41-46.

12 Hunter C, Dimaguila MA, Gal P, Wimmer JE Jr, Ransom JL, Carlos RQ, Smith M, Davanzo CC: Effect of routine probiotic, Lactobacillus reuteri DSM 17938, use on rates of necrotizing enterocolitis in neonates with birthweight $<1000$ grams: a sequential analysis. BMC Pediatr 2012;12:142. 
13 Luoto R, Isolauri E, Lehtonen L: Safety of Lactobacillus GG probiotic in infants with very low birth weight: twelve years of experience. Clin Infect Dis 2010;50:1327-1328.

14 Manzoni P, Lista G, Gallo E, Marangione P, Priolo C, Fontana P, Guardione R, Farina D: Routine Lactobacillus rhamnosus GG administration in VLBW infants: a retrospective, 6-year cohort study. Early Hum Dev 2011; 87(suppl 1):S35-S38.

-15 Sari FN, Eras Z, Dizdar EA, Erdeve O, Oguz SS, Uras N, Dilmen U: Do oral probiotics affect growth and neurodevelopmental outcomes in very low-birth-weight preterm infants? Am J Perinatol 2012;29:579-586.

$\checkmark 16$ Chou IC, Kuo HT, Chang JS, Wu SF, Chiu HY, Su BH, Lin HC: Lack of effects of oral probiotics on growth and neurodevelopmental outcomes in preterm very low birth weight infants. J Pediatr 2010;156:393-396.

17 Romeo MG, Romeo DM, Trovato L, Oliveri S, Palermo F, Cota F, Betta P: Role of probiotics in the prevention of the enteric colonization by candida in preterm newborns: incidence of late-onset sepsis and neurological outcome. J Perinatol 2011;31:63-69.

-18 Rouge C, Piloquet H, Butel MJ, Berger B, Rochat F, Ferraris L, Des Robert C, Legrand A, de la Cochetiere MF, N'Guyen JM, Vodovar M, Voyer M, Darmaun D, Roze JC: Oral supplementation with probiotics in very-lowbirth-weight preterm infants: a randomized, double-blind, placebo-controlled trial. Am J Clin Nutr 2009;89:1828-1835.

19 Shanahan F: A commentary on the safety of probiotics. Gastroenterol Clin North Am 2012;41:869-876.

20 Prescott SL, Wiltschut J, Taylor A, Westcott L, Jung W, Currie H, Dunstan JA: Early markers of allergic disease in a primary prevention study using probiotics: 2.5-year follow-up phase. Allergy 2008;63:1481-1490.

-21 Deshpande GC, Rao SC, Keil AD, Patole SK: Evidence-based guidelines for use of probiotics in preterm neonates. BMC Medicine 2011; 9:92.

22 Deshpande GRS, Patole S, Bulsara M: Probiotics for prevention of necrotizing enterocolitis in preterm VLBW neonates - systematic review of randomised controlled trials. (update 2012). 4th Congress of the European Academy of Paediatric Societies (EAPS), Istanbul, 2012.

23 Deshpande G, Shingde V, Downe L, Leroi M, Xiao J: Routine probiotics for preterm neonates: experience in a tertiary Australian neonatal intensive care unit. J Paediatr Child Health 2013;49:50.

24 Vandenplas Y, Veereman-Wauters G: Probiotics: fishing in the ocean. J Pediatr Gastroenterol Nutr 2012;54:4-5.

25 Claud EC: First do no harm. J Pediatr Pharmacol Ther 2012;17:298-301.
26 Deshpande G, Rao S, Patole S, Bulsara M: Updated meta-analysis of probiotics for preventing necrotizing enterocolitis in preterm neonates. Pediatrics 2010;125:921-930.

27 Jacobs SE, Tobin JM, Opie G, Donath S, Pirotta M, Tabrizi SN, Morley CJ, Garland SM, for the ProPrems Study Group: The Proprems randomised trial investigating the effects of probiotics on late onset sepsis in very preterm infants. Pediatric Academy Society Meeting (PAS), Washington, 2013.

28 Roberts D, Dalziel S: Antenatal corticosteroids for accelerating fetal lung maturation for women at risk of preterm birth. Cochrane Database Syst Rev 2006:CD004454.

29 McGuire W, Anthony MY: Donor human milk versus formula for preventing necrotising enterocolitis in preterm infants: systematic review. Arch Dis Child Fetal Neonatal Ed 2003;88:F11-F14.

30 Patole SK, de Klerk N: Impact of standardised feeding regimens on incidence of neonatal necrotising enterocolitis: a systematic review and meta-analysis of observational studies. Arch Dis Child Fetal Neonatal Ed 2005; 90:F147-F151.

31 Bell EF, Acarregui MJ: Restricted versus liberal water intake for preventing morbidity and mortality in preterm infants. Cochrane Database Syst Rev 2008:CD000503.

32 Pammi M, Abrams SA: Oral lactoferrin for the prevention of sepsis and necrotizing enterocolitis in preterm infants. Cochrane Database Syst Rev 2011:CD007137.

33 Darlow BA, Graham PJ: Vitamin A supplementation to prevent mortality and shortand long-term morbidity in very low birthweight infants. Cochrane Database Syst Rev 2011:CD000501.

34 Reuman PD, Duckworth DH, Smith KL, Kagan R, Bucciarelli RL, Ayoub EM: Lack of effect of Lactobacillus on gastrointestinal bacterial colonization in premature infants. Pediatr Infect Dis 1986;5:663-668.

35 Kitajima H, Sumida Y, Tanaka R, Yuki N, Takayama H, Fujimura M: Early administration of Bifidobacterium breve to preterm infants: randomised controlled trial. Arch Dis Child Fetal Neonatal Ed 1997;76:F101-F107.

36 Dani C, Biadaioli R, Bertini G, Martelli E, Rubaltelli FF: Probiotics feeding in prevention of urinary tract infection, bacterial sepsis and necrotizing enterocolitis in preterm infants. A prospective double-blind study. Biol Neonate 2002;82:103-108.

37 Costalos C, Skouteri V, Gounaris A, Sevastiadou S, Triandafilidou A, Ekonomidou C, Kontaxaki F, Petrochilou V: Enteral feeding of premature infants with Saccharomyces boulardii. Early Hum Dev 2003;74:89-96.

38 Bin-Nun A, Bromiker R, Wilschanski M, Kaplan M, Rudensky B, Caplan M, Hammerman C: Oral probiotics prevent necrotizing enterocolitis in very low birth weight neonates. J Pediatr 2005;147:192-196.
39 Lin HC, Su BH, Chen AC, Lin TW, Tsai CH, Yeh TF, Oh W: Oral probiotics reduce the incidence and severity of necrotizing enterocolitis in very low birth weight infants. Pediatrics 2005; 115:1-4.

40 Manzoni P, Mostert M, Leonessa ML, Priolo C, Farina D, Monetti C, Latino MA, Gomirato G: Oral supplementation with Lactobacillus casei subspecies rhamnosus prevents enteric colonization by Candida species in preterm neonates: a randomized study. Clin Infect Dis 2006;42:1735-1742.

41 Mohan R, Koebnick C, Schildt J, Schmidt S, Mueller M, Possner M, Radke M, Blaut M: Effects of Bifidobacterium lactis Bb12 supplementation on intestinal microbiota of preterm infants: a double-blind, placebo-controlled, randomized study. J Clin Microbiol 2006;44:4025-4031.

-42 Stratiki Z, Costalos C, Sevastiadou S, Kastanidou O, Skouroliakou M, Giakoumatou A, Petrohilou V: The effect of a bifidobacter supplemented bovine milk on intestinal permeability of preterm infants. Early Hum Dev 2007;83:575-579.

43 Lin HC, Hsu CH, Chen HL, Chung MY, Hsu JF, Lien RI, Tsao LY, Chen CH, Su BH: Oral probiotics prevent necrotizing enterocolitis in very low birth weight preterm infants: a multicenter, randomized, controlled trial. Pediatrics 2008; 122:693-700.

44 Samanta M, Sarkar M, Ghosh P, Ghosh J, Sinha M, Chatterjee S: Prophylactic probiotics for prevention of necrotizing enterocolitis in very low birth weight newborns. J Trop Pediatr 2009;55:128-131.

- 45 Braga TD, da Silva GA, de Lira PI, de Carvalho Lima M: Efficacy of Bifidobacterium breve and Lactobacillus casei oral supplementation on necrotizing enterocolitis in verylow-birth-weight preterm infants: a doubleblind, randomized, controlled trial. Am J Clin Nutr 2011;93:81-86.

46 Hikaru U KS, Yayoi S, Hiromichi S, Hiroaki S, Yoshikazu O, Seigo S, Satoru N, Toshaiki S, Yuichiro Y: Bifidobacteria prevents preterm infants from developing infection and sepsis. Int J Probiotics Prebiotics 2010;5:33-36.

47 Sari FN, Dizdar EA, Oguz S, Erdeve O, Uras N, Dilmen U: Oral probiotics: Lactobacillus sporogenes for prevention of necrotizing enterocolitis in very low-birth weight infants: a randomized, controlled trial. Eur J Clin Nutr 2011;65:434-439.

- 48 Al-Hosni M, Duenas M, Hawk M, Stewart LA, Borghese RA, Cahoon M, Atwood L, Howard D, Ferrelli K, Soll R: Probiotics-supplemented feeding in extremely low-birth-weight infants. J Perinatol 2012;32:253-259. 
49 Rojas MA, Lozano JM, Rojas MX, Rodriguez VA, Rondon MA, Bastidas JA, Perez LA, Rojas C, Ovalle O, Garcia-Harker JE, Tamayo ME, Ruiz GC, Ballesteros A, Archila MM, Arevalo M: Prophylactic probiotics to prevent death and nosocomial infection in preterm infants. Pediatrics 2012;130:e1113-e1120.

50 Fernandez-Carrocera LA, Solis-Herrera A, Cabanillas-Ayon M, Gallardo-Sarmiento RB, Garcia-Perez CS, Montano-Rodriguez R, Echaniz-Aviles MO: Double-blind, randomised clinical assay to evaluate the efficacy of probiotics in preterm newborns weighing less than 1,500 $\mathrm{g}$ in the prevention of necrotising enterocolitis. Arch Dis Child Fetal Neonatal Ed 2013;98:F5-F9.
51 Sadowska-Krawczenko I KP, Polak A, Wietlicka-Piszcz M, Szajewska H: Lactobacillus rhamnosus A TC A07FA for preventing necrotizing enterocolitis in very-low-birth-weight preterm infants: a randomized controlled trial (preliminary results). Pediatria Polska 2012;87:139-145.

$52 \mathrm{Ke} \mathrm{D}, \mathrm{Su}$ Z, Li L, et al: Effects of Bifico supplement for prevention of necrotizing enterocolitis in preterm infants: a randomized controlled trial. Chin Pediatr Emerg Med 2008; 12:69-71.

53 Huang B YH, Huang X: Probiotics supplementation for prevention of necrotizing enterocolitis in very low birth weight neonates: a randomized controlled trial. J Guangdong Med Coll 2009;27:37-39.
54 Di MLX: Effects of bifidobacterium supplementation for prevention of necrotizing enterocolitis in preterm infants: a randomized controlled trial. Zhong Guo She Qu Yi Shi 2010;231:69.

55 Ren X, Na B, Ristow B, Whooley MA, Schiller NB: Usefulness of diastolic dominant pulmonary vein flow to predict hospitalization for heart failure and mortality in ambulatory patients with coronary heart disease (from the Heart and Soul Study). Am J Cardiol 2009; 103:482-485.

56 Garland SM, Tobin JM, Pirotta M, Tabrizi SN, Opie G, Donath S, Tang ML, Morley CJ, Hickey L, Ung L, Jacobs SE: The ProPrems trial: investigating the effects of probiotics on late onset sepsis in very preterm infants. BMC Infect Dis 2011;11:210. 